ARTICLE

https://doi.org/10.1038/s41467-021-26490-7

\title{
OPEN
}

\section{Full shell coating or cation exchange enhances luminescence}

Yi Zhang (1) ${ }^{1,3}$, Pengpeng Lei ${ }^{1,3}$, Xiaohui Zhu ${ }^{2 凶} \&$ Yong Zhang (i] ${ }^{1 凶}$

Core-shell structure is routinely used for enhancing luminescence of optical nanoparticles, where the luminescent core is passivated by an inert shell. It has been intuitively accepted that the luminescence would gradually enhance with the coverage of inert shell. Here we report an "off-on" effect at the interface of core-shell upconversion nanoparticles, i.e., regardless of the shell coverage, the luminescence is not much enhanced unless the core is completely encapsulated. This effect indicates that full shell coating on the luminescent core is critical to significantly enhance luminescence, which is usually neglected. Inspired by this observation, a cation exchange approach is used to block the energy transfer between core nanoparticle and surface quenchers. We find that the luminescent core exhibits enhanced luminescence after cation exchange creates an effective shell region. These findings are believed to provide a better understanding of the interfacial energy dynamics and subsequent luminescence changes.

\footnotetext{
${ }^{1}$ Department of Biomedical Engineering, Faculty of Engineering, National University of Singapore, Singapore City 117583 , Singapore. ${ }^{2}$ School of Environmenta and Chemical Engineering, Shanghai University, Shanghai 200444, China. ${ }^{3}$ These authors contributed equally: Yi Zhang, Pengpeng Lei.

凶email: xhzhu@shu.edu.cn; biezy@nus.edu.sg
} 
anthanide-doped nanocrystals have been extensively investigated due to their great promise in multiplexing sensing ${ }^{1-3}$, photovoltaics $^{4-6}$, LED (light emitting diode) display ${ }^{7-9}$, etc. Among them, lanthanide-doped upconversion nanoparticles (UCNPs) represent a class of optical materials that are capable of transforming low energy excitation into high energy luminescence ${ }^{10,11}$. Particularly, benefiting from the ability of upconverting long-wavelength radiation to short-wavelength emission, lanthanide-doped UCNPs have drawn increasing interests for biological applications because of the deeper tissue penetration depth, weaker background interference, and fewer photodamage endowed by the long-wavelength excitations ${ }^{12-14}$.

Typically, lanthanide-doped UCNPs are doped with two types of ions, sensitizers (e.g., $\mathrm{Yb}^{3+}$ and $\mathrm{Nd}^{3+}$ ) and activators (e.g., $\mathrm{Er}^{3+}, \mathrm{Tm}^{3+}$, and $\left.\mathrm{Eu}^{3+}\right)$, of which sensitizers absorb the incident light and transfer excitation energy to activator for luminescence emission. However, for the small-sized UCNPs, the total surface area per unit volume of the particle would increase as the particle size decreases, which may provide more luminescent quenching centers (e.g., surface defects, surface oscillators, etc. $)^{15}$. In light of this issue, various approaches have been proposed in order to improve the luminescence of nanosized UCNPs, including dye-sensitization strategy ${ }^{16,17}$, coupling with surface plasmon ${ }^{18,19}$, local structural engineering ${ }^{20-22}$, etc. ${ }^{23,24}$. Nevertheless, construction of core-shell architecture is still considered as one of the widely used methods to enhance luminescence of UCNPs ${ }^{25}$. For example, Zhou et al. recently reported a core-multi-shell design to alleviate crores-relaxation and promote interfacial energy transfer process, which achieved an upconversion luminescence quantum yield (UCQY) of $6.34 \%$ $\left(4.5 \mathrm{~W} \mathrm{~cm}^{-2}\right)^{26}$. Homann et al. proposed to use anhydrous rareearth acetates to prepare core-shell UCNPs $(45 \mathrm{~nm})$ and reported a UCQY value of $9 \%\left(30 \mathrm{~W} \mathrm{~cm}^{-2}\right)$, which was close to that of the bulk counterpart $(10.3 \%)$ at the same power density ${ }^{27}$.

As for the mechanism of luminescence enhancement via coreshell engineering, Wang et al. firstly reported that coating of a thin inert shell could retain the optical integrity of luminescent core and also effectively reduce emission losses caused by the surface quenching effects ${ }^{28}$. Later, it was proved that the inert shell could decouple the surface and concentration quenching processes for colloidal lanthanide-doped nanocrystals, thus allowing for high-dopant concentrations in the luminescent core $^{29}$. More recently, time-resolved spectroscopic studies indicate that the surface of UCNPs can be gradually passivated with the thickness of inert shell. However, when the UCNP surface is totally passivated, further increasing shell thickness would lead to slight decrease in the emission intensity due to some potential non-radiative quenching pathways from the interface ${ }^{30}$. Based on traditional understanding, it has been intuitively accepted that coating of an inert shell can act as a protective barrier that shields the luminescent UCNP core from its surrounding quenching centers. Nevertheless, the underlying picture of surface quenching dynamics through core-shell interface has not been well elucidated. Despite some discussion of this issue ${ }^{29}$, there are very few studies that directly report a synchronous correlation between a step-wise surface passivation and resulting luminescence change for the core-shell UCNPs. To address these issues, it is necessary to prepare core-shell UCNPs with different shell coverage and to study its relationship with energy transfer and luminescence emission.

In this work, core-shell UCNPs with various shell coverage ratios are demonstrated using silica coated Janus nanoparticles as a template. By increasing the shell coverage, the luminescence intensity of the UCNPs is not much enhanced unless the core nanoparticle is completely covered by the inert shell. In another word, significant enhancement in the luminescence intensity is only observed when a full shell coating is applied. This "off-on" effect in the core-shell UCNPs has not been systematically characterized before and the influence of the shell coverage on the luminescence emission has long been neglected. Furthermore, our time-course study shows that both the emission intensity and color of the highly doped UCNPs vary as the full shell thickness increases. Based on this discovery, a simple post-synthesis approach via cation exchange is developed to eliminate the surface-energy transfer from the core nanoparticle to surface quenching centers, which results in a similar luminescence enhancement effect as the full shell coating. These findings are believed to offer fundamental insights into the mechanisms and process of surface quenching and inspire the design of novel nanostructures with much enhanced luminescence.

\section{Results}

Synthesis of $\mathrm{NaErF}_{4} / \mathrm{SiO}_{2} @ \mathrm{NaYF}_{4}$ Janus nanoparticles. In order to gain insights into the correlation between surface energy dynamics and luminescent properties, we have specifically developed an approach to synthesize core-shell structured $\mathrm{NaErF}_{4} / \mathrm{SiO}_{2} @ \mathrm{NaYF}_{4}$ Janus nanoparticles with tunable shell coverage (Fig. 1a). In a typical procedure, monodispersed $\beta$ $\mathrm{NaErF}_{4}$ UCNPs were firstly synthesized using a co-precipitation method (Fig. 1b) ${ }^{31}$. Subsequently, a dense silica layer was coated anisotropically on the $\mathrm{NaErF}_{4}$ core by a surfactant-templating method, forming a Janus nanoparticle containing a hydrophobic $\mathrm{NaErF}_{4}$ core and a hydrophilic $\mathrm{SiO}_{2}$ shell. Afterwards, part of the $\mathrm{SiO}_{2}$ shell was removed by buffered oxide etchant (BOE), exposing more hydrophobic surface for further growth of the $\mathrm{NaYF}_{4}$ shell.

As illustrated in Fig. 1a, asymmetric coverage of $\mathrm{SiO}_{2}$ shell on the $\mathrm{NaErF}_{4}$ core is a prerequisite for the fabrication of $\mathrm{NaErF}_{4} /$ $\mathrm{SiO}_{2} @ \mathrm{NaYF}_{4}$ Janus nanoparticles. In this study, a reverse microemulsion method was used, in which cetyltrimethyl ammonium bromide (CTAB) was employed as the micellar template and tetraethyl orthosilicate (TEOS) as the silicon precursor. This approach is employed because highly concentrated CTAB surfactants $\left(3 \mathrm{mg} \mathrm{mL}^{-1}\right)$ in the water-oil mixture can lead to the aggregation of CTAB micelles on one side of the UCNP surface, and therefore offer nucleation sites for the growth of $\mathrm{SiO}_{2}$ shell through hydrolysis of TEOS precursors. Moreover, the morphology and $\mathrm{SiO}_{2}$ coverage can be precisely tuned by varying the amount of TEOS precursors added. For example, both the $\mathrm{SiO}_{2}$ coverage ratio (Supplementary Fig. 1a-e) and average hydrodynamic diameters (Supplementary Fig. 1f) can be gradually increased via the addition of TEOS precursors.

Based on the construction of $\mathrm{NaErF}_{4} / \mathrm{SiO}_{2}$ Janus nanoparticles, we verified the feasibility of the direct growth of $\mathrm{NaYF}_{4}$ shell on the $\mathrm{NaErF}_{4} / \mathrm{SiO}_{2}$ nanoparticles. Supplementary Fig. 2a and b present the TEM images of $\mathrm{NaErF}_{4} / \mathrm{SiO}_{2}$ Janus nanoparticles with $\mathrm{SiO}_{2}$ coverage ratio of $0 \%$ and $100 \%$. As shown in Supplementary Fig. 2c, the $\mathrm{NaYF}_{4}$ shell can grow uniformly on the bare $\mathrm{NaErF}_{4}$ core (i.e., $0 \% \mathrm{SiO}_{2}$ coverage) and form a core-shell structure. However, for the silica-coated $\mathrm{NaErF}_{4}$ nanoparticle (i.e., $100 \%$ $\mathrm{SiO}_{2}$ coverage), the $\mathrm{NaYF}_{4}$ phase does not grow on it but instead nucleates separately (Supplementary Fig. 2d). This is because silica tends to form a thin layer around $\mathrm{NaErF}_{4}$ nanoparticle at the beginning of hydrolysis process and cover the whole particle surface over time (Supplementary Fig. 1a-d). Notably, the hydrophilic $\mathrm{SiO}_{2}$ coating formed on $\mathrm{NaErF}_{4}$ core would prohibit the growth of hydrophobic $\mathrm{NaYF}_{4}$ layer. Therefore, the undesired thin portion of the $\mathrm{SiO}_{2}$ shell should be removed in order to expose some of the $\mathrm{NaErF}_{4}$ core surface for the growth of $\mathrm{NaYF}_{4}$ shell.

Although hydrofluoric acid (HF) is a well-known silica removal etchant, it is a highly corrosive liquid and may cause potential 
a

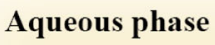

b

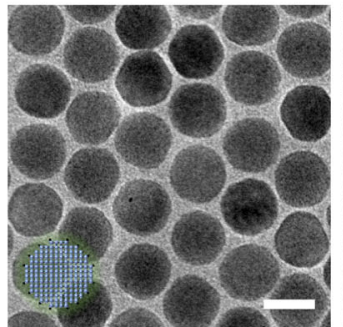

d

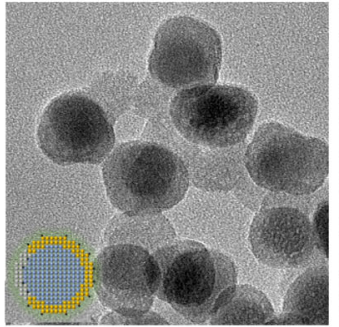

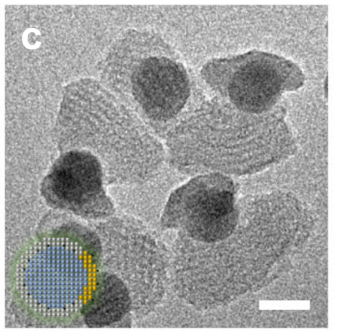

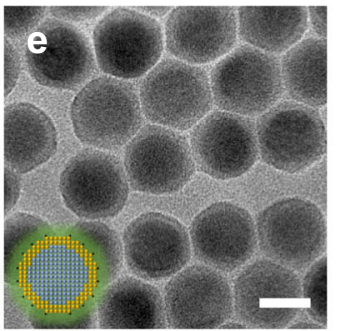

j

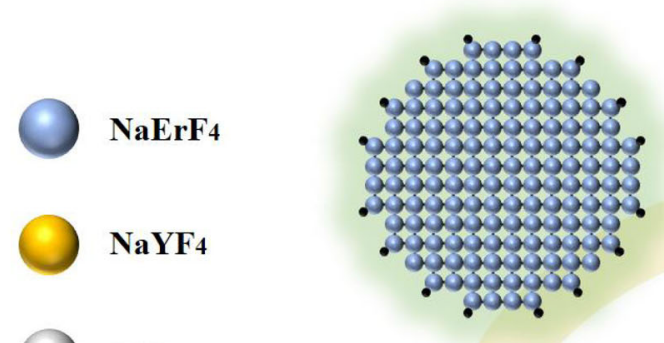

\section{f}

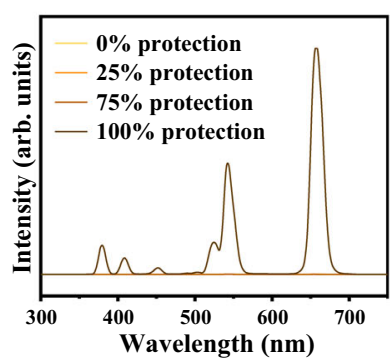

h

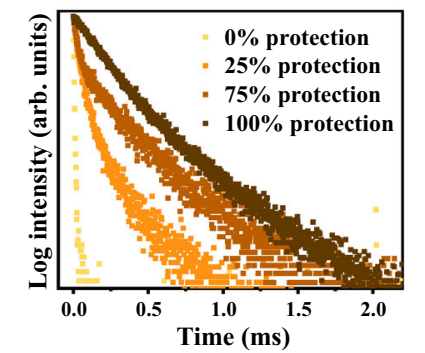

Oil phase

BOE

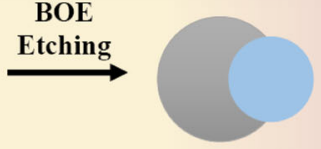

Solvothermal

Synthesis

TEOS: Tetraethyl orthosilicate BOE: Buffered oxide etchant 
Fig. 1 Synthesis and spectroscopic characterization of core-shell structured $\mathrm{NaErF}_{\mathbf{4}} / \mathrm{SiO}_{\mathbf{2}} @ \mathrm{NaYF}_{\mathbf{4}}$ Janus nanoparticles with controllable coverage ratio of $\mathbf{N a Y F}_{\mathbf{4}}$ inert shell. a Schematic showing the synthesis process of core-shell structured $\mathrm{NaErF}_{4} / \mathrm{SiO}_{2} @ \mathrm{NaYF}_{4}$ Janus nanoparticles. The surface of $\mathrm{NaErF}{ }_{4}$ UCNP (blue) was anisotropically coated by a hydrophilic $\mathrm{SiO}_{2}$ shell (gray) via hydrolysis of TEOS (tetraethyl orthosilicate). After etching treatment by BOE

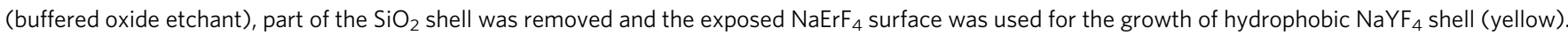
b-e TEM image of $\mathrm{NaErF}_{4}$ (0\% protection), core-shell structured $\mathrm{NaErF}_{4} / \mathrm{SiO}_{2} @ 25 \% \mathrm{NaYF}_{4}$ (25\% protection), $\mathrm{NaErF}_{4} / \mathrm{SiO}_{2} @ 75 \% \mathrm{NaYF}_{4}(75 \%$ protection), and $\mathrm{NaErF}_{4} @ \mathrm{NaYF}_{4}\left(100 \%\right.$ protection). Scale bar: $20 \mathrm{~nm}$. f The upconversion emission spectra core-shell structured $\mathrm{NaErF}_{4} / \mathrm{SiO}_{2} @ \mathrm{NaYF}_{4}$ Janus nanoparticles with $0 \%$ protection, $25 \%$ protection, $75 \%$ protection and $100 \%$ protection upon excited by $980 \mathrm{~nm} \mathrm{laser} \mathrm{light}\left(3 \mathrm{~W} \mathrm{~cm}^{-2}\right)$. g Comparison of upconversion emission spectra core-shell structured $\mathrm{NaErF}_{4} / \mathrm{SiO}_{2} @ \mathrm{NaYF}_{4}$ Janus nanoparticles with 0\% protection, 25\% protection, $75 \%$ protection and $100 \%$ protection in the spectral range from $500 \mathrm{~nm}$ to $700 \mathrm{~nm}$. h, i Decay curve at $542 \mathrm{~nm}$, and $658 \mathrm{~nm}$ of core-shell structured $\mathrm{NaErF}_{4} / \mathrm{SiO}_{2} @ \mathrm{NaYF}_{4}$ Janus nanoparticles with 0\% protection, 25\% protection, 75\% protection and 100\% protection. $\mathbf{j}$ Schematic showing the change at composition, luminescence and energy quenching pathways of core-shell structured $\mathrm{NaErF}_{4} / \mathrm{SiO}_{2} @ \mathrm{NaYF}_{4}$ Janus nanoparticles with an increased $\mathrm{NaYF}_{4}$ shell protection.

averaged zeta potential values for the $\mathrm{NaErF}_{4} @ \mathrm{SiO}_{2}$ Janus nanoparticles before and after BOE etching are measured to be $-39.97 \pm 2.08$ and $-16.57 \pm 0.29 \mathrm{mV}$ (Supplementary Fig. 4c), further confirming the partial removal of negatively charged silica. It is worth to mention that no evident change in the upconversion luminescence profiles of UCNPs is observed before and after BOE etching (Supplementary Fig. 4d), indicating the BOE etching has little influence on the upconversion luminescence.

Following the successful etching process, the $\mathrm{NaErF}_{4} / \mathrm{SiO}_{2}$ Janus nanoparticle were obtained and used as seeds for the growth of $\mathrm{NaYF}_{4}$ shell. Notably, $\mathrm{NaYF}_{4}$ shell is critical in enhancing the luminescence emission, while $\mathrm{SiO}_{2}$ shell provides little protection as it can not passivate surface defects of luminescent core ${ }^{32}$. Here, the protection ratio of $\mathrm{NaYF}_{4}$ shell is defined as follows:

$$
\text { Protection ratio }(\%)=1-\text { silica coverage ratio }(\%)
$$

Figure 1c-e and Supplementary Fig. 5 present the TEM images of core-shell structured $\mathrm{NaErF}_{4} / \mathrm{SiO}_{2} @ \mathrm{NaYF}_{4}$ Janus nanoparticles with different protection ratios of $\mathrm{NaYF}_{4}$ shell $(25 \%, 75 \%$, and $\left.100 \%\left(\mathrm{NaErF}_{4} @ \mathrm{NaYF}_{4}\right)\right)$, which show that the as-prepared Janus nanoparticle consists of the following parts: the $\mathrm{NaErF}_{4} \mathrm{UCNP}$ core, the $\mathrm{SiO}_{2}$ shell covering one side of the core, and the $\mathrm{NaYF}_{4}$ shell on the other side.

Spectroscopic study of core-shell structured $\mathrm{NaErF}_{4} / \mathrm{SiO}_{2} @$ $\mathrm{NaYF}_{4}$ Janus nanoparticles. Figure if compares the upconversion luminescence intensities of core-shell structured $\mathrm{NaErF}_{4} / \mathrm{SiO}_{2} @$ $\mathrm{NaYF}_{4}$ nanoparticles under $980 \mathrm{~nm}$ laser excitation $\left(3 \mathrm{~W} \mathrm{~cm}^{-2}\right)$ with different protection ratios of $\mathrm{NaYF}_{4}$ shell, i.e., $25 \%$ protection $\left(\mathrm{NaErF}_{4} / \mathrm{SiO}_{2} @ 25 \% \mathrm{NaYF}_{4}\right), 75 \%$ protection $\left(\mathrm{NaErF}_{4} / \mathrm{SiO}_{2} @ 75 \%\right.$ $\left.\mathrm{NaYF}_{4}\right)$, and $100 \%$ protection $\left(\mathrm{NaErF}_{4} @ \mathrm{NaYF}_{4}\right)$. The bare $\mathrm{NaErF}_{4}$ core nanoparticle ( $0 \%$ protection) serves as the control group for comparison. Surprisingly, with the protection ratio of $\mathrm{NaYF}_{4}$ shell increased from $0 \%$ to $25 \%$, and to $75 \%$, the upconversion luminescence intensity remains almost unchanged in the spectral range from $500 \mathrm{~nm}$ to $700 \mathrm{~nm}$ (Fig. 1g). Only when a full $\mathrm{NaYF}_{4}$ shell ( $100 \%$ protection) is deposited on the $\mathrm{NaErF}_{4}$ core, the luminescence intensity can be recovered and dramatically improved, by about 2500 times (Supplementary Figure 6). Previous work showed that the inert shell could act as a shield to protect the luminescent core from surface quenchers ${ }^{28}$. In that case, evident enhancement in luminescence intensity should be anticipated when more surface defects are passivated with the protection of $\mathrm{NaYF}_{4}$ shell. However, our results clearly suggest that the luminescence intensity of UCNP core does not synchronously improve with continuous passivation of exposed surface defects. Instead, an "off-on" effect exists at the core-shell interface, meaning that partial coverage of inert shell to any degree contributes little to the luminescence enhancement, and a full coverage with the inert shell is critically necessary.

In lanthanide-doped nanocrystals, the luminescence emission intensity would decrease when the dopant ion concentration exceeds a threshold, typically referred to as "concentration quenching". It has been well established that an inert shell could reduce the coupling between surface and concentration quenching effects via suppressing energy migration to the surface quenchers ${ }^{29,33}$. Figure $1 \mathrm{~h}$ and $\mathrm{i}$ present the upconversion luminescence decay curves of green emission $(542 \mathrm{~nm})$ and red emission $(658 \mathrm{~nm})$ for $\mathrm{NaErF}_{4} / \mathrm{SiO}_{2} @ \mathrm{NaYF}_{4}$ Janus nanoparticles with different protection ratios of $\mathrm{NaYF}_{4}$ shell. It can be observed that the upconversion luminescence lifetime for both green and red emissions generally increase with the increased protection ratios of $\mathrm{NaYF}_{4}$ shell. The enhancement in lifetime does indicate longer time of excitation states remaining in the system when more surface defects are gradually recovered by the coating of $\mathrm{NaYF}_{4}$ shell. However, as mentioned in Fig. If and g, the upconversion luminescence intensity exhibits no evident enhancement with the increase of $\mathrm{NaYF}_{4}$ shell coverage only until the $\mathrm{NaErF}_{4}$ core surface is fully protected. Generally, for the $\mathrm{NaErF}_{4}$ core nanoparticle, some internal defects (e.g., vacancy and interstitial defects) may exist and quench the luminescence (Fig. 1j). Besides, when the size of the particle decreases, the total surface area per volume will increase because of the higher surface-to-volume ratio, which promotes surface-related deactivations due to more exposure to the surface defects (e.g., crystal disorder and non-crystallization) as well as capping ligands and solvent molecules with strong vibrations ${ }^{34,35}$. In this regard, these surface-related quenching processes can affect the luminescence of as-synthesized $\mathrm{NaErF}_{4} /$ $\mathrm{SiO}_{2} @ \mathrm{NaYF}_{4}$ Janus nanoparticles via following routes ${ }^{36}$ (Fig. 1j):

i. Direct deactivation. Photoexcited Er ions located on (or close to) the particle surface are non-radiatively deactivated by the neighboring quenchers.

ii. Energy migration induced quenching. This refers to the quenching process, in which the excitation energy of internal photoexcited Er ions randomly migrates to other Er ions around the surface or directly to the surface quenching site.

Notably, as these surface-related processes can be considered as a form of Förster resonance energy transfer (FRET) ${ }^{37}$, the FRET efficiency via dipole-dipole coupling significantly depends on the separation distance between energy donor and energy acceptor with an inverse $6^{\text {th }}$ power law:

$$
E=\frac{1}{1+\left(\frac{r}{R}\right)^{6}}
$$

where $E$ is the efficiency of energy transfer, $R$ is the Förster distance and $r$ is the distance between the pair of energy donor (i.e., photoexcited $\mathrm{Er}$ ion) and energy acceptor (quenching 
center). As a result, only when a full inert $\mathrm{NaYF}_{4}$ shell is coated on the $\mathrm{NaErF}_{4}$ core, the increased distance between luminescent core and surrounding quenching centers can greatly prevent the quenching of excited Er ions around the surface and also curb the migration of excitation energy to the surrounding quenchers.

In addition to shell coverage, we have further investigated the influence of thickness of incomplete shell on the luminescence intensity of $\mathrm{NaErF}_{4} / \mathrm{SiO}_{2} @ \mathrm{NaYF}_{4}$ Janus nanoparticles. As shown in Supplementary Fig. 7a, with increasing the thickness of the incomplete $\mathrm{NaYF}_{4}$ shell $(75 \%$ coverage) from $0 \mathrm{~nm}$, to $5 \mathrm{~nm}$ and to $10 \mathrm{~nm}$, the luminescence intensity still remains almost unchanged. This is a stark contrast to previous results that the luminescence intensity for core-shell UCNPs should generally exhibit a thickness-dependent behavior ${ }^{29,30,38}$. Also, other than $\mathrm{NaErF}_{4}$ core, we have additionally used the low-doped luminescent core, $\mathrm{NaYF}_{4}: 20 \% \mathrm{Yb}, 2 \% \mathrm{Er}$, to study the influence of $\mathrm{NaYF}_{4}$ shell coverage on the luminescence intensity (Supplementary Fig. 7b). Similar to the case of $\mathrm{NaErF}_{4} / \mathrm{SiO}_{2} @ \mathrm{NaYF}_{4}$, the luminescence intensity of $\mathrm{NaYF}_{4}: 20 \% \mathrm{Yb}, 2 \% \mathrm{Er} / \mathrm{SiO}_{2} @ \mathrm{NaYF}_{4}$ still barely improves with increasing the coverage ratio of $\mathrm{NaYF}_{4}$ shell from $0 \%$ to $75 \%$. Only when a full $\mathrm{NaYF}_{4}$ shell is coated on the $\mathrm{NaYF}_{4}: \mathrm{Yb}, \mathrm{Er}$ core, the upconversion luminescence intensity can then be recovered and drastically improved. In other words, the well-studied parameters such as shell thickness and dopant concentration in previous studies, have little influence on the luminescent intensity, provided that the luminescent core is not completely covered by the inert shell. Therefore, based on the results in Fig. 1 and Supplementary Fig. 7 , it is rather clear that no matter how to tune the coverage and thickness of the outer shell as well as the dopant concentration, the luminescence does not change accordingly unless the surface of the core nanoparticle is fully encapsulated. The existence of such "offon" effect could be due to the reason that as long as the luminescent core is not completely covered by the inert shell, the exposed surface can still act as weak spots where the majority of excitation energy is dissipated via the migration to the surface quenchers and results in little enhancement in emission intensity.

To further understand the evolution of luminescent profiles with the coating of $\mathrm{NaYF}_{4}$ shell on the $\mathrm{NaErF}_{4}$ core, we have performed a time-course study on the growth of core-shell structured $\mathrm{NaErF}_{4} @ \mathrm{NaYF}_{4}$ UCNPs (Fig. 2a). Our strategy was to start with the bare $\mathrm{NaErF}_{4}$ core in the solution, and then mix into the shell precursor to initiate the epitaxial growth of $\mathrm{NaYF}_{4}$ shell. Once the reaction is started by heating the mixture to required temperature, we sampled at different time intervals throughout the synthesis process. In Fig. $2 \mathrm{~b}$, upconversion spectra of $\mathrm{NaErF}_{4}$ core and core-shell $\mathrm{NaErF}_{4} @ \mathrm{NaYF}_{4}$ UCNPs upon excitation by $980 \mathrm{~nm}$ laser light $\left(3 \mathrm{~W} \mathrm{~cm}^{-2}\right)$ are presented for samples obtained at different time points. Over the time course, there is a general increase in the emission intensity of upconversion spectra. In order to make a more direct comparison, the ratio of green to red band $(G / R)$ at each of the time course points are plotted in the inset in Fig. 2b. In terms of the $G / R$ values, there are no significant differences among samples taken at $0 \mathrm{~min}$, and $9 \mathrm{~min}$, but a sharp increase was observed in the subsequent time points. Specifically, the $G / R$ value maximizes $(>0.6)$ at $12 \mathrm{~min}$, and then abruptly drops until $30 \mathrm{~min}$ point and the subsequent $\mathrm{G} / \mathrm{R}$ values remain quite stable over the rest of the time course. Figure $2 \mathrm{c}$ presents the lifetime decays of green and red upconversion luminescence of $\mathrm{NaErF}_{4}$ core and core-shell $\mathrm{NaErF}_{4} @ \mathrm{NaYF}_{4}$ UCNPs at different time points. The average decay time of the green upconversion luminescence of the $\mathrm{NaErF}_{4}$ core is calculated to be only $6.1 \mu \mathrm{s}$, which suggests the excitation energy is nonradiatively lost due to the rapid energy migration to the surface quenchers. On the contrary, the lifetimes of green emission for core-shell $\mathrm{NaErF}_{4} @ \mathrm{NaYF}_{4}$ UCNPs are significantly increased. This indicates that the nonradioactive process previously occurring on the bare $\mathrm{NaErF}_{4}$ core is now greatly suppressed by the protection of the inert $\mathrm{NaYF}_{4}$ shell. Similar to green emission decays, the lifetime of red upconversion luminescence of core-shell $\mathrm{NaErF}_{4} @ \mathrm{NaYF}_{4} \mathrm{UCNPs}$ is also much longer than that of core $\mathrm{NaErF}_{4}$. These results reconfirm that the surface quenching dominates the energy loss process. Another interesting observation is that the lifetime for the red emission monochromatically increases over time, while the lifetime for the green emission increases initially but starts to decrease since the time point of $12 \mathrm{~min}$. The decrease of lifetime for the green emission is an indication of the enhancement of the cross-relaxation process between $\mathrm{Er}^{3+}$ ions over time, i.e., ${ }^{4} \mathrm{~F}_{7 / 2}+{ }^{4} \mathrm{I}_{11 / 2} \rightarrow{ }^{4} \mathrm{~F}_{9 / 2}+{ }^{4} \mathrm{~F}_{9 / 2}$ (Supplementary Fig. 8), since this leads to depopulation of green emitting level ${ }^{4} \mathrm{~F}_{7 / 2}$ and the population of red emitting states ${ }^{4} \mathrm{~F}_{9 / 2}$.

It should be noted that the $\mathrm{Er}^{3+}$ ions in the $\mathrm{NaErF}_{4} @ \mathrm{NaYF}_{4}$ core-shell UCNPs have dual functions, as both sensitizers and activators. On one hand, the $\mathrm{Er}^{3+}$ ions can directly harvest the incident $980 \mathrm{~nm}$ laser light as sensitizers. On the other hand, the excited $\mathrm{Er}^{3+}$ ions can radiatively transit to the ground states through releasing green and red lights. As shown in Fig. 2d, for the bare $\mathrm{NaErF}_{4}$ core, its outer surface is exposed to a large amount of quenching centers. Upon illumination by $980 \mathrm{~nm}$ laser light, the energy transfer (ET) process from $\mathrm{Er}^{3+}$ to surface quenchers can be readily established, which significantly lowers the emission intensity due to the substantial energy loss on the surface. However, once the full inert $\mathrm{NaYF}_{4}$ shell starts to grow on the $\mathrm{NaErF}_{4}$ core, the $\mathrm{Er}^{3+}$ ions are protected from the surface quenchers by the $\mathrm{NaYF}_{4}$ shell. When the thickness of $\mathrm{NaYF}_{4}$ shell is low $(\sim 1 \mathrm{~nm})^{39}$, the surface defects are partly respired, which preferentially promotes the green emission and causes the increase of $G / R$ value. As the thickness of $\mathrm{NaYF}_{4}$ shell goes up, the energy loss by the ET process from $\mathrm{Er}^{3+}$ ions to the surface defects is further prohibited, resulting in the prominent preservation of excitation energies. Under such circumstance, the absorbed excitation power is high enough to maintain the active energy transfer between neighboring $\mathrm{Er}^{3+}$ ions and may lead to adequate populations in the ${ }^{4} \mathrm{I}_{11 / 2}$ and ${ }^{4} \mathrm{~F}_{7 / 2}$ states. Therefore, the possibility of cross relaxation (CR) process between ${ }^{4} \mathrm{I}_{11 / 2}$ and ${ }^{4} \mathrm{~F}_{7 / 2}$ states is greatly raised and the number of ions in the ${ }^{4} \mathrm{~F}_{9 / 2}$ states is accordingly increased, which dramatically enhances the red emission (Supplementary Fig. 8).

Tuning surface energy dynamic via cation exchange. In light of the dominant role of surface-involved energy transfer in controlling luminescent profiles of UCNPs, we moved forward to optimize upconversion intensity by tailoring interfacial energy dynamics via a facile post-treatment. Specifically, a hightemperature ion exchange method is used to enhance the luminescence emission of UCNPs (Fig. 3a). In brief, pre-synthesized $\mathrm{NaErF}_{4}$ nanoparticles were mixed with $\mathrm{YCl}_{3}$ solution at elevated temperature $\left(300^{\circ} \mathrm{C}\right)$ in order to obtain a new composite via cation exchange process, $\mathrm{NaErF}_{4} @ \mathrm{Y}$. Although surface cations on the nanoparticles are replaced by $\mathrm{Y}^{3+}$ ions, the hexagonal structure of $\mathrm{NaErF}_{4}$ phase can still be maintained (Fig. 3b). Besides, the TEM images and the size distribution analysis also reveal that the morphology and size of the $\mathrm{NaErF}_{4}$ nanoparticles do not significantly change during the ion exchange (Fig. 3c, d; Supplementary Fig. 9). The energy-dispersive X-ray spectroscopy (EDS) spectra (Fig. 3e and f) also confirm the presence of $\mathrm{Y}$ element for cation-exchanged $\mathrm{NaErF}_{4} @ \mathrm{Y}$ nanoparticles. Moreover, elemental mapping images of a single $\mathrm{NaErF}_{4} @ \mathrm{Y}$ nanoparticle show that $\mathrm{Na}$, $\mathrm{Er}$, and $\mathrm{F}$ elements are uniformly distributed on the nanoparticles while Y elements are mainly located on the outmost layer, indicating that ion exchange mainly occurs on the surface (see Fig. 3g). In addition, we have also used X-ray photoelectron spectroscopy 
a

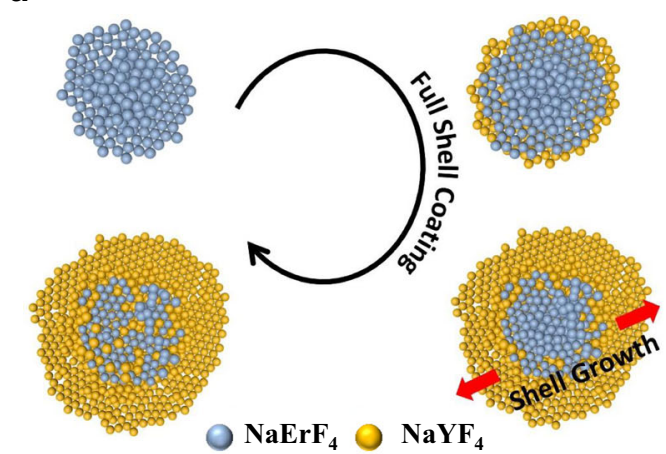

C

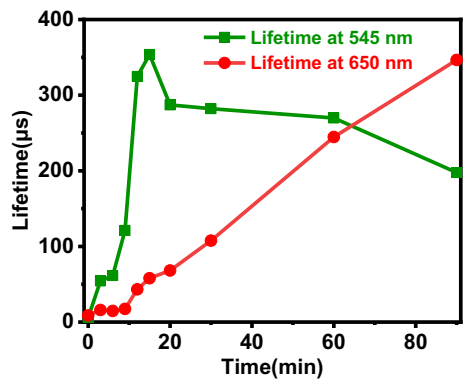

d b

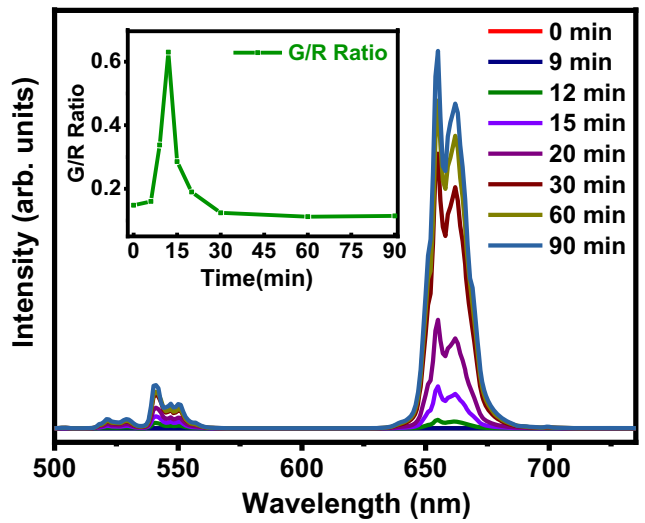

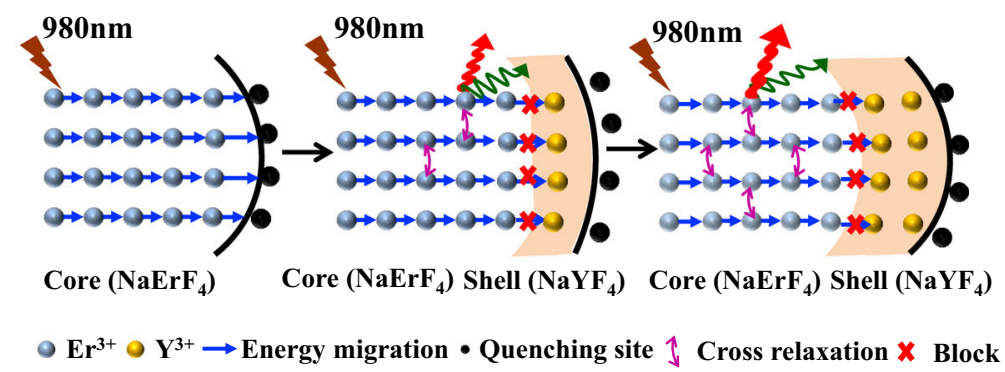

Fig. 2 Time-course study on the growth of core-shell $\mathbf{N a E r F}_{\mathbf{4}} @ \mathbf{N a Y F}_{\mathbf{4}} \mathbf{U C N P s}$. a Schematic of the growing process of full NaYF $\mathrm{F}_{4}$ shell (yellow) on the $\mathrm{NaErF}_{4}$ core (blue). During the full shell coating process, the $\mathrm{NaYF}_{4}$ shell would grow along both sides (red arrow) of the luminescent $\mathrm{NaErF}_{4}$ core. b The changes of upconversion emission spectra under $980 \mathrm{~nm}$ laser light $\left(3 \mathrm{~W} \mathrm{~cm}{ }^{-2}\right.$ ) over time. Inset is the variations of green to red ratio over time. c The lifetime of red and green emissions over time. $\mathbf{d}$ The mechanism of the surface protection of $\mathrm{NaErF}_{4}$ core by $\mathrm{NaYF}_{4}$ shell with different thickness. Upon excitation by $980 \mathrm{~nm}$ light, the excitation energy is rapidly transferred to the surface quenchers for bare $\mathrm{NaErF}_{4}$ core. When a thin NaYF $\mathrm{Whell}_{4}$ (shaded region) is coated, the surface defects are partly restored that preferentially promotes the green emission. As the thickness of NaYF $F_{4}$ shell goes up, the energy loss from $\mathrm{Er}^{3+}$ ions to surface defects is further blocked and the possibility of cross relaxation between $\mathrm{Er}^{3+}$ ions is greatly raised, which dramatically enhances the red emission.

(XPS) to analyze the chemical composition of $\mathrm{NaErF}_{4} @ \mathrm{Y}$ nanoparticles before and after cation exchange. As shown in Fig. 3h, i, the signals from $\mathrm{Y}$ elements can be clearly identified from $\mathrm{NaErF}_{4} @ \mathrm{Y}$. However, no Y signals are observed from the XPS spectra of $\mathrm{NaErF}_{4}$ nanoparticles (Supplementary Fig. 10). It is worth mentioning that all the obtained nanoparticles have similar lattice constants compared with $\mathrm{NaErF}_{4}$ nanoparticles (Supplementary Table 1).

For a bare $\mathrm{NaErF}_{4}$ nanoparticle, as its surface is exposed to the surrounding quenchers, the upconversion luminescence intensity is severely reduced, due to the substantial transfer of the excitation energy to the surrounding quenchers (Fig. 4a). However, we reason that cations on the surface of $\mathrm{NaErF}_{4}$ nanoparticles are replaced by inert $\mathrm{Y}^{3+}$ ions through ion exchange so that the pathway of energy migration to surface quenchers can be blocked, which is expected to enhance upconversion luminescence (Fig. 4b). Figure 4c compares the upconversion luminescence spectra of $\mathrm{NaErF}_{4}$ and $\mathrm{NaErF}_{4} @ \mathrm{Y}$ nanoparticles under $980 \mathrm{~nm}$ laser excitation $\left(3 \mathrm{~W} \mathrm{~cm}^{-2}\right)$. As anticipated, the luminescence intensity of $\mathrm{NaErF}_{4} @ \mathrm{Y}$ nanoparticles is obviously stronger than that of $\mathrm{NaErF}_{4}$ nanoparticles, with an enhancement of about 17.2 times. Figure $4 \mathrm{~d}$ presents the luminescence photos of $\mathrm{NaErF}_{4}$ and $\mathrm{NaErF}_{4} @ \mathrm{Y}$ nanoparticles upon illumination by $980 \mathrm{~nm}$ light, which also confirms that the luminescence of $\mathrm{NaErF}_{4} @ \mathrm{Y}$ is significantly brighter than that of $\mathrm{NaErF}_{4}$. Similar behavior can also be observed for the luminescence decay of $\mathrm{Er}^{3+}$ emission at $542 \mathrm{~nm}$ under $980 \mathrm{~nm}$ excitation (Fig. 4e). As expected, the lifetime value is increased from $5.6 \mu$ s to $28.6 \mu \mathrm{s}$. Notably, the lifetime of $\mathrm{Er}^{3+}$ emission at $658 \mathrm{~nm}$ remains almost unchanged (Fig. 4f), indicating that the exchange of $\mathrm{NaErF}_{4}$ nanoparticles with $\mathrm{Y}^{3+}$ ions has a greater influence on the green emitting state.

To further confirm that the cation substitution with $\mathrm{Y}^{3+}$ ions is the main cause of luminescence enhancement, pre-synthesized $\mathrm{NaErF}_{4}$ nanoparticles were preheated for $1 \mathrm{~h}$ at the same temperature to exclude the temperature influence. As shown in Supplementary Figs. 11 and 12, the reheated $\mathrm{NaErF}_{4}$ nanoparticles $\left(\mathrm{NaErF}_{4} @\right.$ Reheating) can maintain the original shape, size, composition and phase structure. It can also be observed the upconversion emission of $\mathrm{NaErF}_{4}$ nanoparticles before and after reheating basically remains constant (Supplementary Fig. 13), indicating that only reheating treatment can not enhance the luminescence intensity $\mathrm{NaErF}_{4}$ nanoparticles.

In addition, $\mathrm{Yb}^{3+}$ ions are also used for ion exchange with $\mathrm{NaErF}_{4}$ nanoparticles to obtain a new composition of nanoparticles $\left(\mathrm{NaErF}_{4} @ \mathrm{Yb}\right)$ to verify whether it has the same luminescence enchantment effect. The characterization in Supplementary Fig. 14 and Supplementary Fig. 15 confirm that $\mathrm{Yb}^{3+}$ ions have been successfully incorporated into $\mathrm{NaErF}_{4}$ nanocrystals. However, unlike $\mathrm{NaErF}_{4} @ \mathrm{Y}$ nanoparticles, the upconversion luminescence of $\mathrm{NaErF}_{4} @ \mathrm{Yb}$ is barely enhanced compared with that of $\mathrm{NaErF}_{4}$ nanoparticles (Supplementary Fig. 16a). A possible explanation is that the energy levels of $\mathrm{Yb}^{3+}$ ions and $\mathrm{Er}^{3+}$ ions are greatly matched so that the energy migration of excitation energy to surface quenchers can not be blocked (Supplementary Fig. 16b).

\section{Discussion}

For the lanthanide-doped upconversion nanoparticles, a common approach to alleviate surface-related quenching effects is to adopt 
a

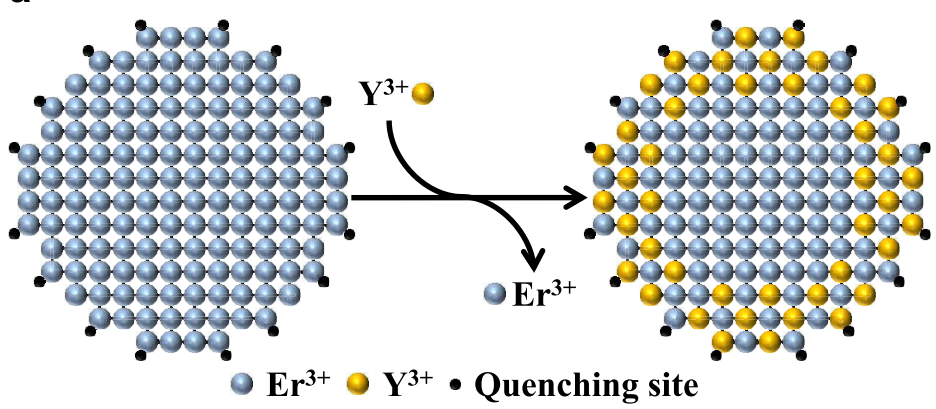

b

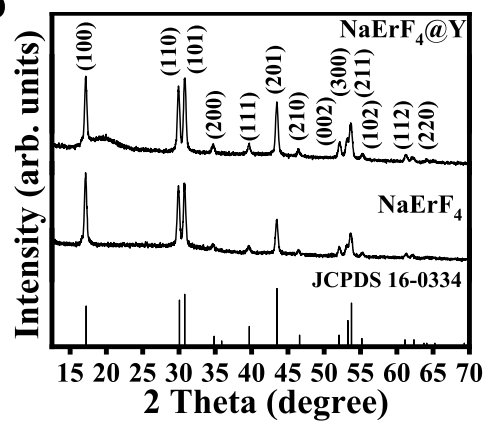

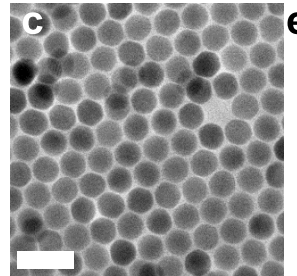
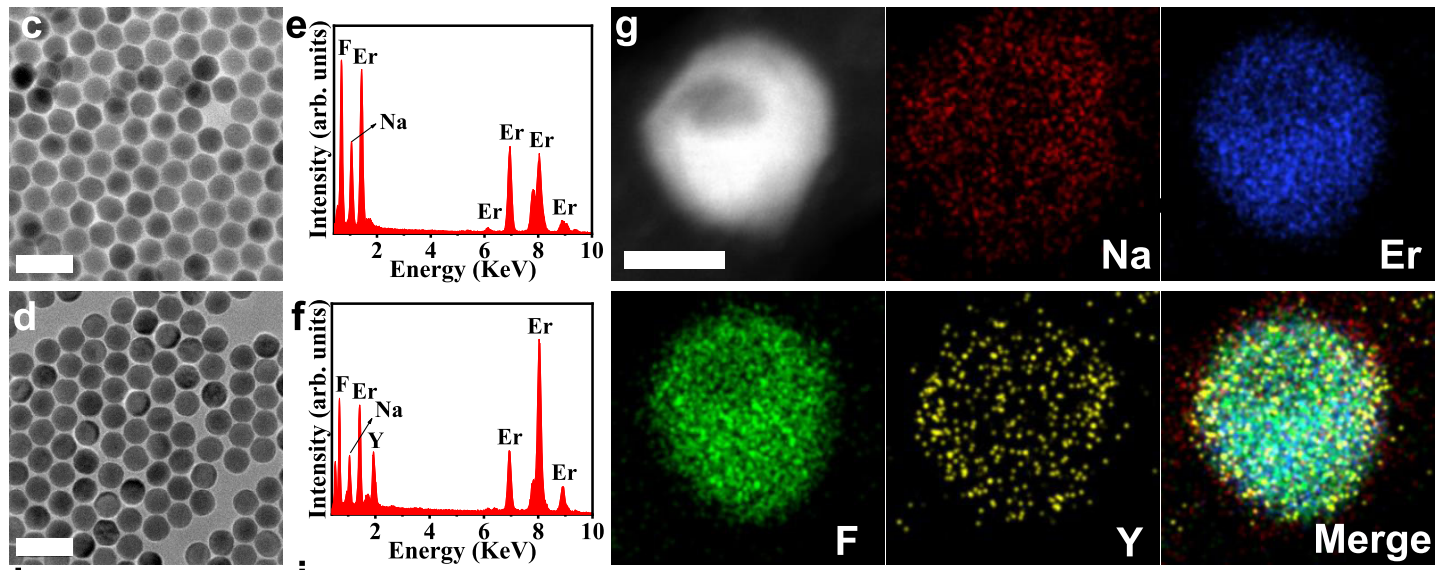

h.
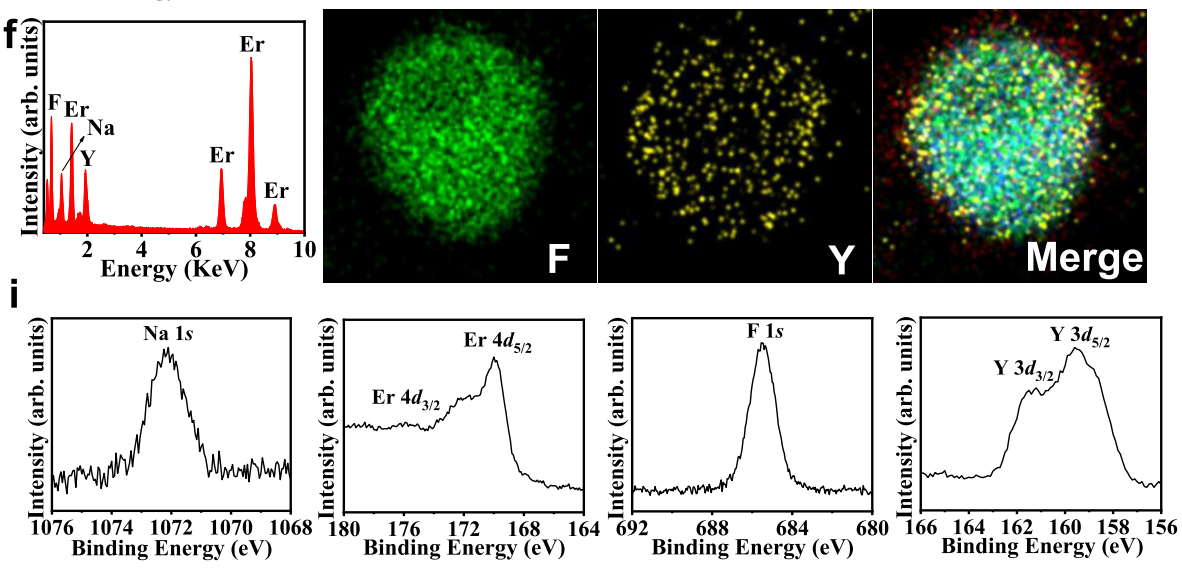

Fig. 3 Structural characterization of $\mathbf{N a E r F}_{\mathbf{4}}$ nanoparticles before and after ion exchange. a Schematic of the NaErF4 core after ion exchange. The $\mathrm{Y}^{3}+$ ions (yellow) would replace some $\mathrm{Er}^{3+}$ ions (blue) on the surface and block the energy transfer to the quenching site. $\mathbf{b} \mathrm{X}$-ray diffraction (XRD) pattern of the $\mathrm{NaErF}_{4}$ nanoparticles, obtained before and after exchange with $\mathrm{Y}^{3+}$ ions (abbreviated as $\mathrm{NaErF}_{4} @ \mathrm{Y}$ ). $\mathbf{c}$, d TEM image of the NaErF $\mathrm{T}_{4}$ nanoparticles and $\mathrm{NaErF}_{4} @ \mathrm{Y}$ nanoparticles, respectively. Scale bar: 50 nm. e, f The EDS line-scan profile of NaErF 4 and NaErF4@Y nanoparticles, respectively. $\mathbf{g}$ HAADFSTEM (high angle annular dark field scanning TEM) of single NaErF $@$ @Y nanoparticle and its corresponding elemental mapping images, Scale bar: 10 nm. h, i Full survey XPS spectrum and detailed spectra ( $\mathrm{Na} 1 \mathrm{~s}, \mathrm{Er} 4 d, \mathrm{~F} 1 \mathrm{~s}$, and Y 3d) of $\mathrm{NaErF}_{4} @ \mathrm{Y}$ nanoparticles.

the core-shell strategy that passivates the luminescent core with an optically inert shell ${ }^{28}$. Due to its great effectiveness and easy fabrication, core-shell engineering has drawn extensive attentions. For example, B. Richards et al. have systematically investigated the crystallographic structure at the interface of core-shell and core-multi-shell nanoparticles, demonstrating that the cation inter-diffusion occurs between core and shell materials during the synthesis ${ }^{15,40}$. Besides, they have recently proposed an energymigration strategy that controls the spatial redistribution of harvested energy from one sensitizing zone to two different emitting zones, which allows for the color-tuning of small-sized upconversion nanoparticles $(<20 \mathrm{~nm})$ with a high quantum yield efficiency up to $3.5 \%\left(60 \mathrm{~W} \mathrm{~cm}^{-2}\right)^{41}$. Moreover, other factors have also been verified to have pronounced influence on the luminescence intensity, such as shell thickness ${ }^{30,38}$, doping concentration $^{29,33}$, refractive index of surrounding solvents ${ }^{37,42}$, synthetic routes ${ }^{27,43}$, etc.

Despite these great efforts, it should be noted that full-shell coating is generally utilized for constructing core-shell structures in these studies. In this context, the impact of this work lies in solving a long-neglected issue in core-shell nanoparticles-that is to probe the relationship between step-wise surface passivation and resulting luminescence change. Only by precisely controlling how shell grows on the luminescent core can we draw accurate conclusions about the passivation-luminescence relationships. In this work, using the surface-templating strategy, the growth of $\mathrm{NaYF}_{4}$ shell on the $\mathrm{NaErF}_{4}$ core can be finely controlled, as shown in Fig. 1a-e. Besides, this strategy can also be employed to fabricate other Janus nanoparticles with dual surface hydrophobicity/hydrophilicity for many potential applications, including nanomotor, multi-modal imaging, cancer therapy, etc. On the successful construction of $\mathrm{NaErF}_{4} / \mathrm{SiO}_{2} @ \mathrm{NaYF}_{4}$ Janus nanoparticles, we have demonstrated an "off-on" effect at the coreshell interface: regardless of the coverage ratio and thickness of the inert shell as well as the doping concentration, the luminescence is not much changed unless the core surface is completely encapsulated. Therefore, this means that the key factor that influences most on the surface passivation of an individual UCNP nanoparticle is the minimum thickness of inert shell instead of the average value. In other words, if the core nanoparticle is not fully coated, it seems that the core surface is little passivated. 
a

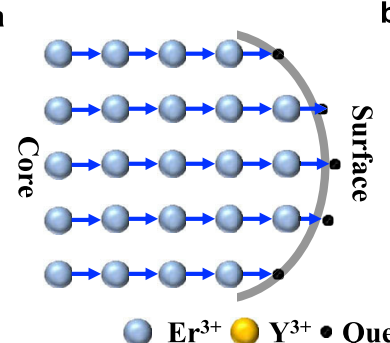

b

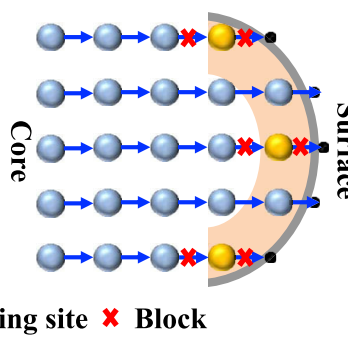

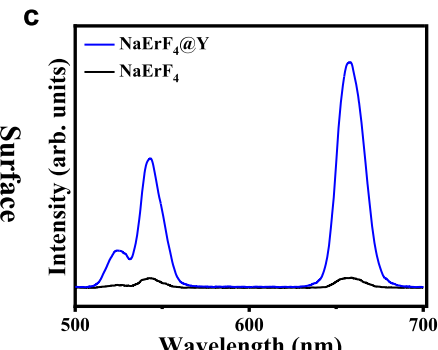

d

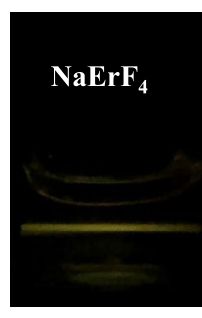

e

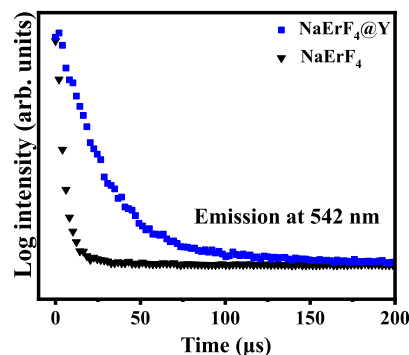

f

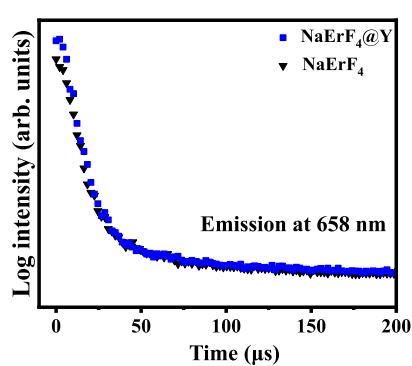

Fig. 4 Spectroscopic study of $\mathbf{N a E r F}_{\mathbf{4}}$ before and after ion exchange. a Schematic diagram of luminescence quenching caused by energy transfer to the surface. The excitation energy would migrate among Er ions (blue) and travel to the quenching site (dark) on the surface. b Proposed mechanism of luminescence enhancement after ion exchange. The $\mathrm{Y}^{3+}$ ions replaced some $\mathrm{Er}^{3+}$ ions on the surface and created an effective shell region (shaded area) such that the energy migration to the surface quenching site was blocked. c, d Upconversion emission spectra and corresponding luminescence photographs of the $\mathrm{NaErF}_{4}$ and $\mathrm{NaErF}_{4} @ \mathrm{Y}$ nanoparticles upon $980 \mathrm{~nm}$ laser excitation $\left(3 \mathrm{~W} \mathrm{~cm}^{-2}\right)$. e, $\mathbf{f}$ Lifetime decay curve of Er $3+$ emission at $542 \mathrm{~nm}$ and $658 \mathrm{~nm}$ from the $\mathrm{NaErF}_{4}$ and $\mathrm{NaErF}_{4} @ \mathrm{Y}$ nanoparticles upon $980 \mathrm{~nm}$ laser excitation $\left(3 \mathrm{~W} \mathrm{~cm}{ }^{-2}\right)$.

Furthermore, it is believed that such "off-on" effect is not only applicable to core-shell UCNPs, but to many other luminescent counterparts, which would also be rather helpful to better understand the interfacial energy dynamics of core-shell nanosystems.

In summary, the long neglected relationship between interfacial quenching dynamics and upconversion luminescence in core-shell UCNPs is elucidated through step-wise passivation of surface defects via a specially designed Janus architecture. Our results clearly indicate that full shell encapsulation on the luminescent core nanoparticle plays decisive roles in enhancing upconversion luminescence intensity. The time-course studies further show that both the upconversion luminescence intensity and color output vary with the thickness of full shell coverage. In light of this understanding, a non-core-shell strategy based cation exchange method is utilized to enhance upconversion luminescence of highly doped UCNPs, and demonstrate similar functionality as the core-shell approach. It is believed that our results offer important insights into the interfacial energy dynamics and may inspire new design of UCNP-based nanocomposites with optimized performance and broader application potentials.

\section{Methods}

We synthesized upconversion nanoparticles using the method described in ref. ${ }^{31}$. Additional experimental details are provided in the Supplementary Note.

Synthesis of $\mathrm{NaErF}_{\mathbf{4}} / \mathrm{SiO}_{\mathbf{2}}$ Janus nanoparticles. Firstly, $3 \mathrm{mg} \mathrm{mL}^{-1} \mathrm{CTAB}$ solution $(10 \mathrm{~mL})$ was mixed with $5 \mathrm{mg} / \mathrm{mL} \mathrm{NaErF}_{4}$ in cyclohexane $(1 \mathrm{~mL})$, followed by $45 \mathrm{~s}$ of sonication using the Sonic Material Vibra-Cell Ultrasonic Processor (SciMed (Asia) Pte Ltd) until a milk-like emulsion formed. Then, the emulsion was transferred to a $25 \mathrm{~mL}$ one-neck round bottom flask and vigorously stirred at $1400 \mathrm{rpm}$ and heated to $70^{\circ} \mathrm{C}$ for $3 \mathrm{~h}$ until full removal of the cyclohexane. The solution would turn back to a clear state. After the solution was cooled down to room temperature, the $\mathrm{NaErF}_{4} @ \mathrm{CTAB}$ solution $\left(0.5 \mathrm{mg} \mathrm{mL}^{-1}, \mathrm{mg} \mathrm{mL}^{-1}\right)$ was transferred to another $25 \mathrm{~mL}$ one-neck round bottom flask. Then, $200 \mu \mathrm{L}$ ammonium hydroxide solution was added into the flask and the solution was kept stirring under $1000 \mathrm{rpm}$. After $30 \mathrm{~min}$, different amount of TEOS was added dropwise into the flask, during which the stirring speed was kept as $1400 \mathrm{rpm}$. After $3 \mathrm{~h}$ of stirring, the Janus nanoparticles were precipitated down by centrifugation and dispersed in $10 \mathrm{~mL}$ DI water and stored for further use. Notably, for the tuning of silica coverage, different amount of TEOS $(15,20,25,30$, and $35 \mu \mathrm{L})$ were added into $\mathrm{NaErF}_{4} @ \mathrm{CTAB}$ solution.

Silica etching. $10 \mathrm{~mL} \mathrm{NaErF} / \mathrm{SiO}_{2}$ solution $\left(0.5 \mathrm{mg} \mathrm{mL}^{-1}\right)$ were mixed with specific amounts of BOE ranging from 5 to $12.5 \mu \mathrm{L}$ to obtain $\mathrm{NaErF}_{4} / \mathrm{SiO}_{2}$ Janus nanoparticles with different $\mathrm{SiO}_{2}$ coverage ratio. The BOE solution was firstly diluted by $1 \mathrm{~mL}$ DI water to reduce the etching speed and achieve uniform etching morphology. The diluted BOE solution was added dropwise by the control a micro syringe pump at a speed of $1 \mathrm{~mL} \mathrm{~h}^{-1}$. Notably, the solution was kept for stirring under $1000 \mathrm{rpm}$. Then, the solution was centrifuged at $15000 \mathrm{rpm}$ for $10 \mathrm{~min}$ and the obtained precipitates were dispersed in $10 \mathrm{~mL}$ ethanol.

Preparation of core-shell structured $\mathrm{NaErF}_{4} / \mathrm{SiO}_{2} @ \mathrm{NaYF}_{4}$ nanoparticles. Typically, based on the core-shell ratio, for every $10 \mathrm{~mL}$ ethanol containing etched $\mathrm{NaErF}_{4} / \mathrm{SiO}_{2}$ Janus nanoparticles, the aqueous solution of $0.03 \mathrm{mmol} \mathrm{YCl}_{3}$ was added into a $100 \mathrm{~mL}$ three-neck flask. After removing the water under $110^{\circ} \mathrm{C}$, the residuals were further dissolved in the mixture of $6 \mathrm{~mL}$ oleic acid and $15 \mathrm{~mL}$ 1 -octadecene and the whole system was maintained at $156^{\circ} \mathrm{C}$ for $10 \mathrm{~min}$ to completely form the RE-oleate complexes (RE: rare elements). Then, the mixture was cooled down to room temperature. The etched Janus $\mathrm{NaErF}_{4} / \mathrm{SiO}_{2}$ nanoparticles dispersed in $10 \mathrm{~mL}$ ethanol were added into the solution and the resulting mixture was heated to $120^{\circ} \mathrm{C}$ to evaporate the ethanol. Upon cooling down to room temperature, followed was the addition of $150 \mu \mathrm{L}$ methanol solution containing $0.12 \mathrm{mmol} \mathrm{NH}_{4} \mathrm{~F}$ and $0.075 \mathrm{mmol} \mathrm{NaOH}$. To remove the methanol, the temperature of the whole mixture was raised to $120^{\circ} \mathrm{C}$ for $10 \mathrm{~min}$. After that, to remove the oxygen and residual methanol, the system was degassed and filled by argon alternatively three times. Subsequently, the whole reaction was raised to $300^{\circ} \mathrm{C}$ and kept for $1 \mathrm{~h}$ under the argon environment. The resulting solution was precipitated by adding the equal volume of acetone and centrifuged at $10000 \mathrm{rpm}$ for $10 \mathrm{~min}$. The precipitates were washed with acetone twice and finally dispersed in $10 \mathrm{~mL}$ cyclohexane and stored for further use.

Synthesis of hexagonal NaErF $\mathbf{F}_{\mathbf{4}} @ \mathbf{Y}$ UCNPs. NaErF $\mathrm{N}_{4} @ \mathrm{Y}$ UCNPs were obtained by ion exchange method. In a typical process, $1 \mathrm{mmol} \mathrm{YCl}_{3}$ aqueous solution was added to a $100 \mathrm{~mL}$ flask. The solution was heated at $120^{\circ} \mathrm{C}$ to fully remove the water. Then, $6 \mathrm{~mL}$ of oleic acid and $15 \mathrm{~mL}$ of 1-octadecene were added to the flask and the mixture was heated to $155^{\circ} \mathrm{C}$ until the solid powder is completely dissolved. The resulting solution was cooled down to room temperature. Subsequently, the pre-synthesized $\mathrm{NaErF}_{4}$ nanoparticles dispersed in cyclohexane $(20 \mathrm{~mL})$ were added. The resulting mixture was heated at $120^{\circ} \mathrm{C}$ for $30 \mathrm{~min}$ to evaporate the cyclohexane. Then, the solution was heated to $300^{\circ} \mathrm{C}$ under argon for $1 \mathrm{~h}$ and cooled down to room temperature. The products were precipitated by addition of acetone, collected by centrifugation, and washed with acetone several 
times. NaErF $@ \mathrm{Yb}$ UCNPs were synthesized by using an identical procedure, except for the use of $\mathrm{YbCl}_{3}$ in the synthesis.

Synthesis of hexagonal NaErF ${ }_{4} @$ Reheating UCNPs. In a typical process, the assynthesized $\mathrm{NaErF}_{4}$ nanoparticles dispersed in cyclohexane $(20 \mathrm{~mL})$ were added. The resulting mixture was heated at $120^{\circ} \mathrm{C}$ for $30 \mathrm{~min}$ to evaporate the cyclohexane. Then, the solution was heated to $300^{\circ} \mathrm{C}$ under argon for $1 \mathrm{~h}$ and then cooled down to room temperature. The products were precipitated by addition of acetone, collected by centrifugation, and washed with acetone several times.

\section{Data availability}

The data that support the findings of this study are available from the corresponding author upon reasonable request. Source data are provided with this paper.

Received: 14 June 2021; Accepted: 5 October 2021;

Published online: 26 October 2021

\section{References}

1. Li, L.-L., Wu, P., Hwang, K. \& Lu, Y. An exceptionally simple strategy for DNA-functionalized up-conversion nanoparticles as biocompatible agents for nanoassembly, DNA delivery, and imaging. J. Am. Chem. Soc. 135, 2411-2414 (2013)

2. Zhang, Z. et al. Upconversion nanoprobes: recent advances in sensing applications. Anal. Chem. 91, 548-568 (2019).

3. Sun, H. et al. White-light emissive upconversion nanoparticles for visual and colorimetric determination of the pesticide thiram. Microchim. Acta 186, 106 (2019).

4. Zhang, H., Chen, Z.-H., Liu, X. \& Zhang, F. A mini-review on recent progress of new sensitizers for luminescence of lanthanide doped nanomaterials. Nano Res. 13, 1795-1809 (2020).

5. Marin, R. \& Jaque, D. Doping lanthanide ions in colloidal semiconductor nanocrystals for brighter photoluminescence. Chem. Rev. 121, 1425-1462 (2021).

6. Cardoso, M. A. et al. Solar spectral conversion based on plastic films of lanthanide-doped ionosilicas for photovoltaics: Down-shifting layers and luminescent solar concentrators. J. Rare Earths 38, 531-538 (2020).

7. Xia, Z. \& Meijerink, A. Ce ${ }^{3+}$-doped garnet phosphors: composition modification, luminescence properties and applications. Chem. Soc. Rev. 46, 275-299 (2017)

8. Yao, J.-S. et al. $\mathrm{Ce}^{3+}$-doping to modulate photoluminescence kinetics for efficient $\mathrm{CsPbBr}_{3}$ nanocrystals based light-emitting diodes. J. Am. Chem. Soc. 140, 3626-3634 (2018)

9. Mir, W. J., Sheikh, T., Arfin, H., Xia, Z. \& Nag, A. Lanthanide doping in metal halide perovskite nanocrystals: spectral shifting, quantum cutting and optoelectronic applications. NPG Asia Mater. 12, 9 (2020).

10. Bettinelli, M., Carlos, L. \& Liu, X. Lanthanide-doped upconversion nanoparticles. Phys. Today 68, 38-44 (2015).

11. Idris, N. M., Jayakumar, M. K. G., Bansal, A. \& Zhang, Y. Upconversion nanoparticles as versatile light nanotransducers for photoactivation applications. Chem. Soc. Rev. 44, 1449-1478 (2015).

12. Idris, N. M. et al. In vivo photodynamic therapy using upconversion nanoparticles as remote-controlled nanotransducers. Nat. Med. 18, 1580-1585 (2012).

13. Zhang, Z. et al. Upconversion superballs for programmable photoactivation of therapeutics. Nat. Commun. 10, 4586 (2019).

14. Teh, D. B. L. et al. A flexi-PEGDA upconversion implant for wireless brain photodynamic therapy. Adv. Mater. 32, 2001459 (2020).

15. Hudry, D. et al. Direct evidence of significant cation intermixing in upconverting core@shell nanocrystals: toward a new crystallochemical model. Chem. Mater. 29, 9238-9246 (2017).

16. Zou, W., Visser, C., Maduro, J. A., Pshenichnikov, M. S. \& Hummelen, J. C. Broadband dye-sensitized upconversion of near-infrared light. Nat. Photonics 6, 560-564 (2012).

17. Garfield, D. J. et al. Enrichment of molecular antenna triplets amplifies upconverting nanoparticle emission. Nat. Photonics 12, 402-407 (2018).

18. Feng, W., Sun, L. D. \& Yan, C. H. Ag nanowires enhanced upconversion emission of NaYF4:Yb,Er nanocrystals via a direct assembly method. Chem. Commun. 4393-4395 https://doi.org/10.1039/b909164e (2009).

19. Zhan, Q., Zhang, X., Zhao, Y., Liu, J. \& He, S. Tens of thousands-fold upconversion luminescence enhancement induced by a single gold nanorod. Laser Photonics Rev. 9, 479-487 (2015).

20. Li, Z., Park, W., Zorzetto, G., Lemaire, J.-S. \& Summers, C. J. Synthesis Protocols for $\delta$-Doped $\mathrm{NaYF}_{4}$ :Yb,Er. Chem. Mater. 26, 1770-1778 (2014).
21. Dong, H. et al. Efficient tailoring of upconversion selectivity by engineering local structure of lanthanides in $\mathrm{Na}_{\mathrm{x}} \mathrm{REF}_{3+\mathrm{x}}$ Nanocrystals. J. Am. Chem. Soc. 137, 6569-6576 (2015).

22. Huang, J. et al. Artificial atomic vacancies tailor near-infrared II excited multiplexing upconversion in core-shell lanthanide nanoparticles. Nano Lett. 20, 5236-5242 (2020).

23. Wang, J. et al. Spectral engineering of lanthanide-doped upconversion nanoparticles and their biosensing applications. Mater. Chem. Front. 5, 1743-1770 (2021)

24. Zhu, X., Zhang, J., Liu, J. \& Zhang, Y. Recent progress of rare-earth doped upconversion nanoparticles: synthesis, optimization, and applications. $A d v$. Sci. 6, 1901358 (2019)

25. Fan, Y., Liu, L. \& Zhang, F. Exploiting lanthanide-doped upconversion nanoparticles with core/shell structures. Nano Today 25, 68-84 (2019).

26. Zhou, B. et al. Enhancing multiphoton upconversion through interfacial energy transfer in multilayered nanoparticles. Nat. Commun. 11, 1174 (2020).

27. Homann, C. et al. $\mathrm{NaYF}_{4}: \mathrm{Yb}, \mathrm{Er} / \mathrm{NaYF}_{4}$ core/shell nanocrystals with high upconversion luminescence quantum Yield. Angew. Chem. Int. Ed. 57, 8765-8769 (2018)

28. Wang, F., Wang, J. \& Liu, X. Direct evidence of a surface quenching effect on size-dependent luminescence of upconversion nanoparticles. Angew. Chem. Int. Ed. 49, 7456-7460 (2010).

29. Johnson, N. J. J. et al. Direct evidence for coupled surface and concentration quenching dynamics in lanthanide-doped nanocrystals. J. Am. Chem. Soc. 139, $3275-3282$ (2017)

30. $\mathrm{Xu}, \mathrm{X}$. et al. Optimising passivation shell thickness of single upconversion nanoparticles using a time-resolved spectrometer. APL Photonics 4, 26104 (2019).

31. Li, Z. \& Zhang, Y. An efficient and user-friendly method for the synthesis of hexagonal-phase $\mathrm{NaYF}_{4}: \mathrm{Yb}, \mathrm{Er} / \mathrm{Tm}$ nanocrystals with controllable shape and upconversion fluorescence. Nanotechnology 19, 345606 (2008).

32. Qian, L. P., Yuan, D., Shun Yi, G. \& Chow, G. M. Critical shell thickness and emission enhancement of $\mathrm{NaYF}_{4}: \mathrm{Yb}, \mathrm{Er} / \mathrm{NaYF}_{4} /$ silica core/shell/shell nanoparticles. J. Mater. Res. 24, 3559-3568 (2009)

33. Wen, S. et al. Advances in highly doped upconversion nanoparticles. Nat. Commun. 9, 2415 (2018).

34. Bian, W., Lin, Y., Wang, T., Yu, X. \& Qiu, J. Direct identification of surface defects and their influence on the optical characteristics of upconversion nanoparticles direct identification of surface defects and their influence on the optical characteristics of upconversion nanoparticles. ACS Nano 12, 623-3628 (2018).

35. Zhang, Y., Zhu, X. \& Zhang, Y. Exploring heterostructured upconversion nanoparticles: from rational engineering to diverse applications. ACS Nano 15, 3709-3735 (2021).

36. Chen, G., Qiu, H., Prasad, P. N. \& Chen, X. Upconversion nanoparticles: design, nanochemistry, and applications in theranostics. Chem. Rev. 114, 5161-5214 (2014)

37. Rabouw, F. T. et al. Quenching Pathways in $\mathrm{NaYF}_{4}: \mathrm{Er}^{3+}, \mathrm{Yb}^{3+}$ upconversion nanocrystals. ACS Nano 12, 4812-4823 (2018).

38. Würth, C., Fischer, S., Grauel, B., Alivisatos, A. P. \& Resch-Genger, U. Quantum yields, surface quenching, and passivation efficiency for ultrasmall core/shell upconverting nanoparticles. J. Am. Chem. Soc. 140, 4922-4928 (2018).

39. Wang, M. et al. Alleviating the emitter concentration effect on upconversion nanoparticles via an inert shell. J. Mater. Chem. C. 5, 1537-1543 (2017).

40. Hudry, D. et al. Interface disorder in large single- and multi-shell upconverting nanocrystals. J. Mater. Chem. C. 7, 1164-1172 (2019).

41. Hudry, D. et al. An enhanced energy migration strategy in upconverting nanocrystals: color-tuning with high quantum yield. J. Mater. Chem. C. 7 , 7371-7377 (2019).

42. Rabouw, F. T., den Hartog, S. A., Senden, T. \& Meijerink, A. Photonic effects on the Förster resonance energy transfer efficiency. Nat. Commun. 5, 3610 (2014).

43. Fischer, S., Swabeck, J. K. \& Alivisatos, A. P. Controlled isotropic and anisotropic shell growth in $\beta-\mathrm{NaLnF}_{4}$ nanocrystals induced by precursor injection rate. J. Am. Chem. Soc. 139, 12325-12332 (2017).

\section{Acknowledgements}

We acknowledge the financial support from Ministry of Education of Singapore (MOE) under its Tier3 and Tierl programme (MOE 2016-T3-1-004, R-397-000-274-112, R-397000-348-114), National Medical Research Council (NMRC/OFIRG/0071/2018, R-397000-317-213), National University of Singapore, National Natural Science Foundation of China (No. 11905123, 81971740, and 31671011), Shanghai Sailing Program (19YF1415200) and Innovative Research Team of High-Level Local Universities in Shanghai. 


\section{Author contributions}

Yo.Z. and X.Z. conceived and supervised the project. Yi.Z., P.L. and X.Z. performed the studies. All authors participated in analyzing the results, preparing the figures, and writing the paper.

\section{Competing interests}

The authors declare no competing interests.

\section{Additional information}

Supplementary information The online version contains supplementary material available at https://doi.org/10.1038/s41467-021-26490-7.

Correspondence and requests for materials should be addressed to Xiaohui Zhu or Yong Zhang.

Peer review information Nature Communications thanks Oscar Loureiro Malta and the other, anonymous, reviewer(s) for their contribution to the peer review of this work.
Reprints and permission information is available at http://www.nature.com/reprints

Publisher's note Springer Nature remains neutral with regard to jurisdictional claims in published maps and institutional affiliations.

\begin{abstract}
BY bution 4.0 International License, which permits use, sharing, adaptation, distribution and reproduction in any medium or format, as long as you give appropriate credit to the original author(s) and the source, provide a link to the Creative Commons license, and indicate if changes were made. The images or other third party material in this article are included in the article's Creative Commons license, unless indicated otherwise in a credit line to the material. If material is not included in the article's Creative Commons license and your intended use is not permitted by statutory regulation or exceeds the permitted use, you will need to obtain permission directly from the copyright holder. To view a copy of this license, visit http://creativecommons.org/licenses/by/4.0/.
\end{abstract}

(C) The Author(s) 2021 